\title{
Aktivitas harian kadal Eutropis multifasciata pada habitat kebun di dataran rendah di Desa Peguyangan, Denpasar - Bali
}

\author{
Daily activity of the common sun skink Eutropis multifasciata at a plantation habitat in \\ low altitude at Peguyangan Village, Denpasar - Bali
}

\author{
Ni Luh Putu Gina Puspita Dewi, Luh Putu Eswaryanti Kusuma Yuni*, Ida Bagus Made Suaskara \\ Program Studi Biologi, Fakultas Matematika dan Ilmu Pengetahuan Alam, Universitas Udayana, \\ Bukit Jimbaran, Bali, Indonesia - 80361 \\ *Email: luh_eswaryanti@unud.ac.id
}

Diterima 22 Juli $2020 \quad$ Disetujui 11 Oktober 2020

\section{INTISARI}

Kadal Eutropis multifasciata merupakan salah satu spesies hewan ektoterm, yang suhu tubuhnya dipengaruhi oleh suhu lingkungan sekitarnya. Penelitian ini bertujuan untuk mengetahui aktivitas harian kadal Eutropis multifasciata yang hidup di dataran rendah. Penelitian ini dilaksanakan dari tanggal 27 Maret - 07 Mei 2019 di habitat kebun dengan tutupan yang rapat pada ketinggian 64 mdpl. Pengamatan dilakukan dengan metode focal animal sampling dengan instantaneous recording. Setiap individu kadal yang dijumpai diamati aktivitasnya selama lima (5) menit dengan interval waktu selama sepuluh (10) detik. Pengamatan aktivitas dilakukan sepanjang hari, dimulai pukul 07.00 hingga 17.00 WITA. Tidak terdapat perbedaan nyata pada aktivitas harian antara individu jantan dan betina kadal Eutropis multifasciata. Persentase aktivitas yang paling banyak dilakukan yaitu mencari makan dengan rata-rata $35,15 \%$ sedangkan aktivitas yang paling sedikit dilakukan adalah aktivitas shuttling memiliki rata-rata 0,68\%. Persentase aktivitas lainnya berturut-turut yaitu moving 24,10\%, overt basking 19,62\%, covert basking $14,29 \%$, cooling $4,69 \%$, dan agresi $1,48 \%$.

Kata kunci: ektoterm, kadal, aktivitas harian

\begin{abstract}
Common Sun Skink Eutropis multifasciata is one species of ectothermic animal, whose body temperature is affected by the temperature of their surrounding environment. This study aims to determine the daily activity of lizards Eutropis multifasciata that live in the lowlands. This research was conducted from 27 March to 07 May 2019 in a plantation habitat with a dense cover at an altitude of 64 masl. Observations were made using focal animal sampling method with instantaneous recording. For each individual lizard found, its activity was observed for five (5) minutes with a ten (10) seconds time interval. Observation of activities carried out throughout the day, starting at 07.00 until 17.00 WITA. There were no significant differences in daily activities between male and female Eutropis multifasciata lizards. Percentage of the most widely performed activities was foraging with an average of $35.15 \%$ while the least performed activities was shuttling with an average of $0.68 \%$. The percentage of other activities were moving $24.10 \%$, overt basking $19.62 \%$, covert basking $14.29 \%$, cooling $4.69 \%$, and aggression $1.48 \%$.
\end{abstract}

Keywords: ectotherm, lizard, daily activity 


\section{PENDAHULUAN}

Kadal merupakan salah satu jenis dari kelompok hewan ektoterm, dimana suhu tubuhnya sangat dipengaruhi oleh lingkungan di sekitarnya (Yuni et al., 2018). Kadal Eutropis multifasciata termasuk ke dalam famili scincidae, dan memiliki ukuran tubuh berkisar antara $5 \mathrm{~cm}$ hingga $32 \mathrm{~cm}$ (Ji et al., 2006). Keberadaan kadal di suatu tempat merupakan indikator terhadap melimpahnya keanekaragaman hayati salah satunya adalah serangga, karena makanan utamanya adalah berbagai macam larva dan serangga yang menjadi hama (Kurniati, 2001). Untuk dapat beraktivitas dengan optimal, maka kadal harus menjaga agar suhu tubuhnya berada di dalam kisaran suhu optimal. Salah satu upaya yang dilakukan adalah dengan melakukan mekanisme termoregulasi.

Termoregulasi adalah suatu mekanisme makhluk hidup untuk mempertahankan suhu internal agar berada di dalam kisaran yang optimal (Campbell, 2004). Mekanisme termoregulasi terjadi dengan mengatur keseimbangan antara perolehan panas dengan pelepasan panas. Kadal merupakan salah satu komponen penyusun ekosistem dan merupakan bagian keanekaragaman hayati yang menghuni kawasan hutan, perkebunan, dan lingkungan masyarakat. Sebagai salah satu komponen ekosistem, kadal memegang peranan penting dalam rantai makanan di lingkungan hidupnya, keseimbangan alam, serta bagi lingkungan manusia. Aktivitas harian kadal dapat mencerminkan lingkungan termal lokal, seperti halnya perbedaan suhu lingkungan di habitatnya. Salah satu contoh adalah pada snow skink (Niveoscincus spp.) dimana kadal melakukan aktivitas berjemur lebih sedikit pada suhu yang panas, dan sebaliknya, banyak mengalokasikan waktunya untuk berjemur pada habitat dengan suhu dingin (Melville and Swain, 1997).

Penelitian tentang efek iklim terhadap aktivitas hewan ektoterm, khususnya kadal, telah banyak dilakukan di wilayah sub tropis (misalnya Melville and Swain, 1997; Wapstra et al., 2001,
2008; Yuni et al., 2015), tetapi belum banyak dilakukan di wilayah tropis terutamanya di Indonesia. Respon yang diberikan oleh hewan ektoterm (termasuk kadal) terhadap suhu lingkungan yang berbeda telah banyak dijadikan acuan untuk memperkirakan efek dari pemanasan global terhadap kehidupan organisme di bumi ini (Huey et al., 2012; Yuni et al., 2018). Pada penelitian ini, aktivitas harian kadal Eutropis multifasciata yang hidup di dataran rendah dipelajari. Secara spesifik, penelitian ini bertujuan untuk mengetahui alokasi yang diberikan oleh kadal Eutropis multifasciata terhadap beberapa kategori aktivitas pada habitat di dataran rendah yang memiliki suhu hangat. Hasil dari penelitian ini akan bermanfaat didalam memprediksi efek dari perubahan iklim di masa mendatang terhadap mahluk hidup, terutamanya golongan ektoterm yang suhu tubuhnya dipengaruhi oleh suhu lingkungan sekitarnya.

\section{MATERI DAN METODE}

\section{Tempat dan waktu penelitian}

Penelitian ini telah dilakukan di Banjar Cengkilung, Desa Peguyangan, Denpasar, Bali (S 08 $35^{\prime} 52.3^{\prime \prime}$, E $\left.115^{\circ} 13^{\prime} 47.2^{\prime \prime}\right)$ pada tanggal 27 Maret - 07 Mei 2019. Lokasi penelitian merupakan habitat kebun dengan tutupan yang rapat seluas $604.87 \mathrm{~m} 2$ (Gambar 1). Lokasi berada pada ketinggian 64 meter diatas permukaan laut dengan suhu udara rata-rata 26.43 $\pm 0.18^{\circ} \mathrm{C}$ (https://id.climate-data.org/location/ 601151/).

\section{Bahan dan alat}

Penelitian ini menggunakan spesies kadal Eutropis multifasciata sebanyak 42 individu (18 individu jantan dan 24 individu betina). Alat- alat yang digunakan dalam penelitian ini meliputi alat pancing beserta umpan ulat hongkong, lembar data, alat tulis yang digunakan untuk mencatat aktivitas harian, penunjuk waktu (timer), spidol warna perak, dan kamera untuk mendokumentasikan kegiatan penelitian. 


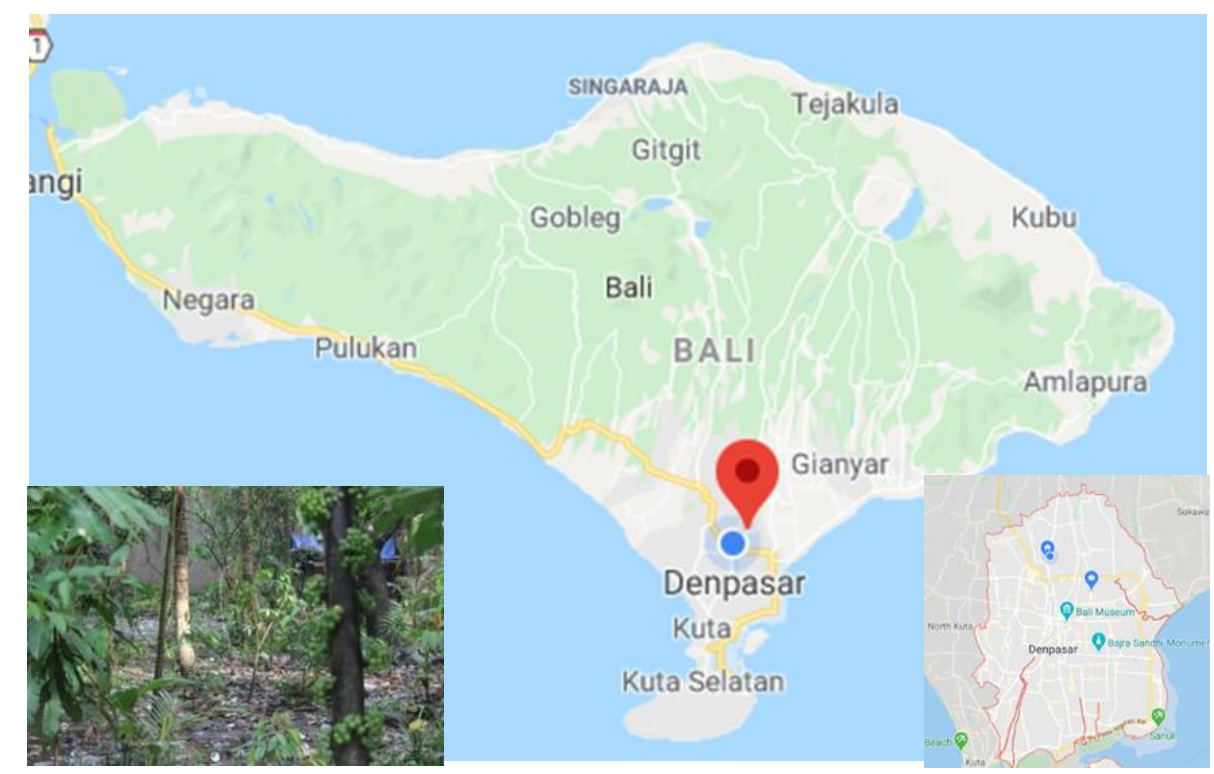

Gambar 1. Habitat Penelitian di dataran rendah, Desa Peguyangan, Denpasar, Bali.

\section{Metode}

Kadal Eutropis multifasciata ditangkap dengan menggunakan pancing dengan mata kail yang halus berisikan ulat hongkong (meal worms) sebagai umpan. Periode penangkapan kadal dibatasi selama dua minggu untuk mengurangi resiko hilangnya tanda yang diberikan pada tubuh kadal karena peristiwa ecdysis. Penentuan jenis kelamin individu dilakukan dengan mengecek jika terdapat hemipenis pada kloaka setiap individu; ketika bagian pangkal ekor ditekan dengan pelan keluar hemipenis berarti individu tersebut adalah jantan, dan sebaliknya. Selain itu penentuan jenis kelamin juga dapat dilihat dari bentuk leher individu kadal Eutropis multifasciata, dimana individu betina memiliki bentuk leher lebih ramping, sedangkan individu jantan memiliki bentuk leher lebih lebar dan besar, terhadap ukuran kepala. Dilakukan pula penomoran dan penandaan dengan menggunakan spidol berwarna perak untuk membedakan jenis kelamin setiap individu; individu jantan diberikan tanda pada bagian leher sedangkan individu betina diberikan tanda pada bagian posterior dorsal. Individu kemudian dilepaskan kembali di tempat dimana ditangkap, segera setelah pengukuran selesai dilakukan.

Pengamatan aktivitas harian dilakukan dengan metode focal animal sampling dengan instantaneous recording. Setiap individu yang dijumpai diamati selama lima (5) menit dengan interval waktu selama sepuluh (10) detik, sehingga didapatkan tiga puluh (30) data per individu per waktu pengamatan. Pengamat berdiri pada jarak \pm 5 meter dari hewan target. Pengamatan aktivitas dilakukan sepanjang hari, dimulai pukul 07.00 hingga 17.00. Pengamatan aktivitas harian kadal Eutropis multifasciata dilakukan dengan mengacu pada kategori aktivitas harian menurut Melville and Swain (1997). Aktivitas harian kadal Eutropis multifasciata yang diamati dikelompokkan menjadi tujuh, yaitu:

a. Overt basking: aktivitas berjemur dibawah sinar matahari dan seluruh bagian tubuhnya terkena paparan cahaya.

b. Covert basking: aktivitas berjemur dibawah sinar matahari, tetapi tidak seluruh tubuhnya terkena paparan cahaya, karena ada bagian tubuhnya yang ditutupi vegetasi atau media lain disekitarnya.

c. Cooling: aktivitas saat kadal berdiam pada tempat yang teduh atau tidak terkena sinar matahari

d. Shuttling: aktivitas termoregulasi yang mencakup gerakan berpindah antara tempat yang terpapar matahari dan yang di naungan (shade).

e. Foraging: aktivitas mencari makan dan memakan makanan, baik sambil bergerak 
ataupun diam, serta sambil menjulurjulurkankan lidahnya (tongue flicking).

f. Moving: aktivitas berpindah tempat, tetapi bukan termasuk aktivitas shuttling maupun foraging.

g. Agresi: aktivitas berkelahi.

Selanjutnya ke tujuh kategori aktivitas harian ini, dapat menunjukkan perilaku kadal Eutropis multifasciata yang hidup di daerah perkebunan. Data aktivitas per kategori yang didapat dirataratakan per satu hari pengamatan selama 25 hari pengamatan lalu diubah menjadi persentase dari setiap kategori aktivitas.

\section{Analisis data}

Pada penelitian ini, SPSS for Windows versi 22 digunakan untuk menganalisis data perbedaan aktivitas harian kadal Eutropis multifasciata. Data aktivitas harian kadal dipresentasikan dalam bentuk grafik rata-rata \pm galat baku. Selanjutya, dilakukan uji normalitas terhadap data yang terkumpul selama 25 hari pengamatan. Untuk setiap hari pengamatan, data aktivitas harian kadal merupakan rata-rata dari aktivitas harian seluruh kadal yang dijumpai yang mana setiap individu hanya dicatat sekali pada setiap hari pengamatan. Data aktivitas harian yang terkumpul dikelompokkan berdasarkan jenis kelamin untuk mengetahui apakah aktivitas harian kadal jantan berbeda dengan kadal betina. Setelah itu dilanjutkan dengan uji $O N E$ WAY ANOVA karena data terdistribusi secara normal.

\section{HASIL}

Dalam penelitian yang berlangsung dari tanggal 27 Maret 2019 sampai dengan tanggal 07 Mei 2019 ini, dapat dikumpulkan 250 jam pengamatan. Jumlah rata-rata individu yang tercatat pada setiap hari pengamatan adalah 8 individu kadal jantan dan 10 individu kadal betina. Berdasarkan pengamatan yang dilakukan diketahui bahwa aktivitas tertinggi kadal Eutropis multifasciata di dataran rendah yaitu aktivitas foraging, sedangkan aktivitas terendah adalah aktivitas shuttling. Untuk aktivitas berjemur, kadal ini dominan melakukan aktivitas overt basking daripada covert basking dengan perbedaan aktivitas 5,33\% (Gambar 2.). Secara detail, alokasi aktivitas harian kadal Eutropis multifasciata di habitat perkebunan di Desa Peguyangan, Denpasar, Bali yang terdapat di dataran rendah yaitu aktivitas overt basking $(19,62 \pm 1,49 \%)$, covert basking (14,29 $\pm 1,29$ $\%)$, cooling $(4,69 \pm 0,78 \%)$, shuttling $(0,68 \pm$ $0,23 \%)$, foraging $(35,15 \pm 1,70 \%)$, moving $(24,10$ $\pm 1,12 \%)$, dan agresi $(1,48 \pm 0,45 \%)$.

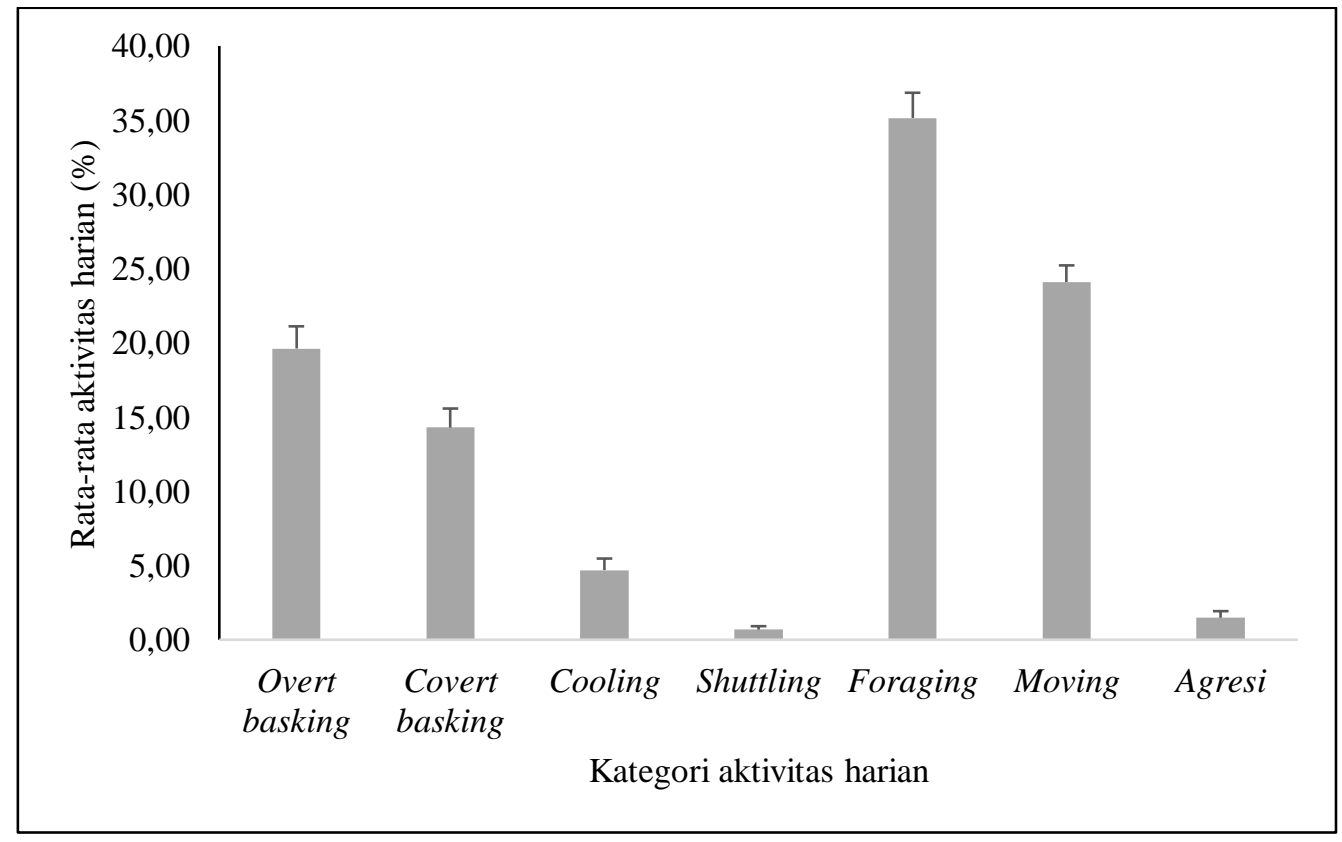

Gambar 2. Alokasi aktivitas harian kadal Eutropis multifasciata di dataran rendah, Desa Peguyangan, Denpasar, Bali 
Tidak ditemukan pula perbedaan aktivitas harian antara individu jantan dan betina pada penelitian ini $(\mathrm{P}>0,05)$. Alokasi aktivitas harian dari kelompok indiviu jantan dan betina ditampilkan pada Tabel 1. Meskipun tidak berbeda secara signifikan, kadal jantan mengalokasikan waktunya lebih banyak untuk foraging, moving dan agresi, sedangkan kadal betina lebih banyak melakukan aktivitas basking, cooling dan shuttling meskipun tidak berbeda secara signifikan dengan kadal jantan menurut analisa statistik (Gambar 3.)

Tabel 1. Aktivitas harian kadal Eutropis multifasciata pada individu jantan dan betina di dataran rendah, Desa Peguyangan, Denpasar, Bali

\begin{tabular}{|c|c|c|c|}
\hline Kategori & Kelamin & Rata-rata \pm Galat baku & Signifikansi \\
\hline \multirow{2}{*}{ Overt basking } & Jantan & $19,76 \pm 2,42 \%$ & \multirow{2}{*}{$F_{1,49}=0,108, \mathrm{P}=0,744$} \\
\hline & Betina & $20,77 \pm 1,87 \%$ & \\
\hline \multirow{2}{*}{ Covert basking } & Jantan & $12,91 \pm 1,93 \%$ & \multirow{2}{*}{$F_{1,49}=0,472, \mathrm{P}=0,495$} \\
\hline & Betina & $14,67 \pm 1,70 \%$ & \\
\hline \multirow{2}{*}{ Cooling } & Jantan & $3,98 \pm 1,11 \%$ & \multirow{2}{*}{$F_{1,49}=0,663, \mathrm{P}=0,420$} \\
\hline & Betina & $5,43 \pm 1,40 \%$ & \\
\hline \multirow{2}{*}{ Shuttling } & Jantan & $0,59 \pm 0,30 \%$ & \multirow{2}{*}{$F_{1,49}=0,008, \mathrm{P}=0,930$} \\
\hline & Betina & $0,62 \pm 0,27 \%$ & \\
\hline \multirow{2}{*}{ Foraging } & Jantan & $35,95 \pm 2,53 \%$ & \multirow{2}{*}{$F_{1,49}=0,259, \mathrm{P}=0,613$} \\
\hline & Betina & $34,14 \pm 2,51 \%$ & \\
\hline \multirow{2}{*}{ Moving } & Jantan & $24,69 \pm 1,78 \%$ & \multirow{2}{*}{$F_{1,49}=0,224, \mathrm{P}=0,638$} \\
\hline & Betina & $23,49 \pm 1,78 \%$ & \\
\hline \multirow{2}{*}{ Agresi } & Jantan & $2,13 \pm 0,88 \%$ & \multirow{2}{*}{$F_{1,49}=1,634, \mathrm{P}=0,207$} \\
\hline & Betina & $0,87 \pm 0,42 \%$ & \\
\hline
\end{tabular}

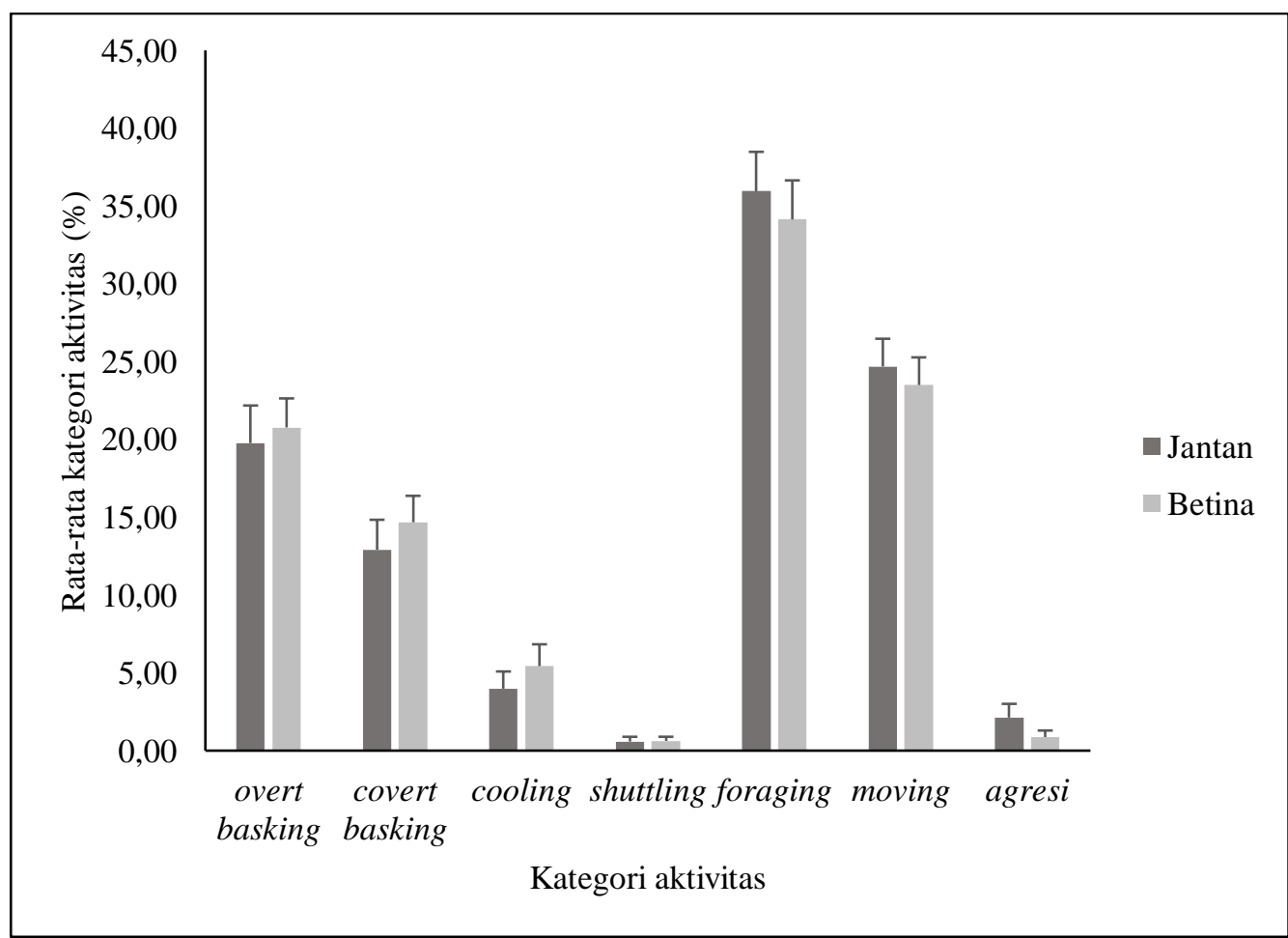

Gambar 3. Aktivitas harian kadal Eutropis multifasciata pada individu jantan dan betina di dataran rendah, Desa Peguyangan, Denpasar, Bali 


\section{PEMBAHASAN}

Pada penelitian ini, kadal Eutropis multifasciata yang hidup di habitat perkebunan yang terletak di daerah bersuhu panas (dataran rendah) di Desa Peguyangan, Denpasar, Bali mengalokasikan paling banyak waktunya untuk aktivitas makan (foraging). Aktivitas makan merupakan aktivitas utama untuk kelangsungan hidup suatu organisme karena memberikan sumber energi untuk dapat melakukan aktivitasaktivitas lainnya (Lundberg, 1985; Yuni, 2002). Aktivitas makan sangat dipengaruhi oleh melimpahnya jumlah makanan di habitatnya. Kadal Eutropis multifasciata merupakan spesies yang oportunistik, makan apa saja yang tersedia di alam. Menurut Vitt and Caldwell (2009) kadal lebih banyak memangsa serangga-serangga kecil berupa semut, rayap, dan lalat, selain itu kadal juga memangsa kodok kecil, dan juga reptil yang lain seperti cicak dan jenis kadal lain yang bertubuh lebih kecil (Das, 2010). Pada penelitian ini, kadal Eutropis multifasciata terlihat memangsa semut, lalat dan serangga kecil lainnya, bahkan pernah terlihat memangsa kadal - kadal kecil yang baru saja dilahirkan serta memangsa ulat buah yang ada pada buah busuk di sekitar kebun.

Pada saat mencari makan, individu-individu kadal Eutropis multifasciata pernah ditemukan berkelahi, perilaku ini termasuk aktivitas agresi. Kadal Eutropis multifasciata sangat mudah untuk berkelahi dikarenakan Eutropis multifasciata merupakan spesies yang territorial dan agresif sehingga mudah berkompetisi dalam mencari makanan, selain itu agresi dapat terjadi ketika perebutan lahan untuk melakukan aktivitas berjemur (Truong, 2005; 2013). Pada penelitian ini, tercatat aktivitas agresi kadal jantan lebih tinggi daripada kadal betina. Aktivitas agresi ini juga dapat terjadi saat musim kawin pada individu jantan untuk mendapatkan betina, perkelahian ini dapat menyebabkan cedera serius seperti luka, putusnya ekor bahkan kematian (Phung, 2013).

Aktivitas berjemur kadal Eutropis multifasciata pada penelitian ini terbagi menjadi 2 yaitu overt basking dan covert basking,
Aktivitas berjemur merupakan bagian utama dari kelangsungan hidup hewan ektoterm terutama kadal, karena suhu tubuhnya sangat dipengaruhi oleh suhu disekitarnya (Yuni et al., 2018). Melalui berjemur kadal melakukan aktivitas termoregulasi yang berguna untuk mempertahankan suhu tubuhnya agar berada di dalam kisaran yang dapat ditolerir (Campbell, 2004; Melville and Swain, 1997). Aktivitas overt basking pada kadal Eutropis multifasciata dalam penelitian ini lebih sering dilakukan di atas pohon, paving, tanah, dan batu. Hal ini dikarenakan tipe habitat yang merupakan kebun dengan tutupan yang rapat, sehingga kadal Eutropis multifasciata harus mencari tempat dengan sinar matahari yang masuk ke lantai kebun untuk mendapatkan panas secara radiasi. Selain itu pada penelitian ini kadal juga terlihat menempelkan tubuhnya di atas substrat bebatuan untuk menerima panas secara konduksi. Bebatuan merupakan substrat yang sangat mudah untuk menghantarkan panas (Campbell, 2004).

Kadal juga melakukan aktivitas covert basking, yaitu berjemur namun beberapa bagian tubuhnya ditutupi naungan, yang bertujuan untuk mengoptimalkan suhu tubuhnya namun juga untuk berkamuflase agar tidak mudah untuk ditemukan oleh predator. Aktivitas cooling pada penelitian ini mencatat individu kadal yang diam di tempat yang teduh pada siang hari. Hal ini bertujuan untuk mengurangi suhu tubuhnya, karena suhu di lingkungannya sudah panas. Hal ini juga dijumpai pada penelitian Hertz and Huey (1981) pada spesies Anolis cybotes, dimana perilaku yang diakibatkan perubahan dalam lingkungan termalnya jelas terlihat pada pilihan habitat dan frekuensi berjemur dari spesies ini. Populasi Anolis cybotes yang hidup di dataran rendah ( $<100 \mathrm{mdpl})$ menempati habitat yang relatif teduh dan jarang berjemur, yang merupakan perilaku untuk menjaga suhu tubuh tetap optimal di lingkungan yang panas. Pada penelitian ini, kadal Eutropis multifasciata betina lebih banyak melakukan aktivitas basking, cooling dan shuttling dibandingkan dengan kadal jantan. Hal ini kemungkinan disebabkan oleh kebutuhan reproduksi kadal betina untuk menjaga 
suhu tubuhnya tetap optimal (Angilletta et al., 2001). Suhu optimal untuk perkembangan embrio pada kadal adalah sekitar $29^{\circ} \mathrm{C}$ (Lin et al., 2008).

Aktivitas moving merupakan aktivitas kadal Eutropis multifasciata berpindah tempat atau berjalan, dan aktivitas ini tidak termasuk aktivitas ketika mencari makan. Pada penelitian ini, aktivitas moving tercatat cukup besar yaitu 24,10\%. Kadal Eutropis multifasciata melakukan aktivitas berpindah jika panas yang diterima sudah cukup untuk menyeimbangkan suhu tubuhnya, sedangkan jika panas yang diterima belum cukup maka kadal Eutropis multifasciata akan berjemur, hingga suhu tubuhnya mencapai kisaran optimal. Adapun aktivitas shuttling yaitu aktivitas termoregulasi yang mencakup gerakan berpindah antara tempat yang ternaungi dan terkena paparan sinar matahari. Aktivitas ini sangat jarang $(0,68 \%)$ dilakukan oleh individu kadal Eutropis multifasciata pada saat penelitian berlangsung. Aktivitas shuttling pada kadal biasanya dilakukan sesuai dengan situasi lingkungannya, yang mana akan lebih sering dilakukan pada habitat yang memiliki tutupan yang sangat rapat atau teduh (Spellerberg, 1972; Maia et al., 2012).

Secara umum, hasil penelitian ini dapat menjelaskan bagaimana respon dari kadal, yang mewakili golongan hewan ektoterm, terhadap suhu lingkungan panas yang tercermin melalui alokasi waktu terhadap berbagai aktivitas yang dilakukan oleh kadal Eutropis multifasciata tersebut. Lebih lanjut, informasi yang diperoleh ini dapat menjadi acuan didalam memprediksi efek perubahan iklim terhadap kehidupan hewan ektoterm.

\section{SIMPULAN}

Berdasarkan hasil penelitian yang telah dilakukan di Desa Peguyangan, Denpasar mengenai aktivitas harian kadal Eutropis multifasciata pada individu jantan dan betina tidak terdapat perbedaan yang signifikan dari 7 kategori aktivitas harian, sehingga didapatkan pengalokasian waktu tertinggi tanpa membedakan individu jantan dan betina yaitu aktivitas foraging dengan rata-rata $35,15 \%$, dan aktivitas terendah yaitu shuttling memiliki ratarata $0,68 \%$, sedangkan untuk aktivitas berjemur kategori covert basking lebih sedikit 14,29\% daripada kategori overt basking 19,62\%. Aktivitas moving didapatkan 24,10\%, cooling $4,69 \%$, dan agresi $1,48 \%$.

\section{UCAPAN TERIMA KASIH}

Penulis mengucapkan terima kasih kepada Bapak Drs. Job Nico Subagio, M.Si, Ibu Dra. Ni Luh Watiniasih, M.Sc., Ph.D., dan Bapak Prof. Dr. Ir. I Wayan Kasa, M.Rur., Sc. atas waktu, saran, dan masukannya.

\section{KEPUSTAKAAN}

Angilletta MJ, Sears MW, Winters RS. 2001. Seasonal variation in reproductive effort and its effect on offspring size in the lizard Sceloporus undulatus. Herpetologica 57:365-75.

Campbell NA. 2004. Biologi. Edisi kelima. Jilid 1. Jakarta: Erlangga

Das I. 2010. Reptiles of South-East Asia. New Holland Publishers: UK.

Hertz PE, Huey B. 1981. Compensation for altitudinal changes in the thermal environment by some anolis lizards on hispaniola ecological society of america stable. Ecology 62(3): 515-521.

Huey RB, Pianka ER. 1981. Ecological consequences of foraging mode. Ecology. 62: 991-999.

Ji X, Lin CX, Lin LH, Qiu QB, Du Y. 2007. Evolution of viviparity in warm-climate lizards: an experimental test of the maternal manipulation hypothesis. J Evol Biol 20: 1037-1045.

Kurniati H. 2001. Analisis ekologi relung intraspesifik kadal Sphenomorphus variegates ditinjau dari mangsa alaminya. Zoo Indonesia 28: 8-11.

Lin CX, Zhang L, Ji X. 2008. Influence of pregnancy on locomotor performances of the 
skink, Mabouya multifasciata: why do females shift thermal preferences when pregnant? Zoology 111: 188-195

Lundberg P. 1985. Time-budgeting by Starlings Sturnus vulgaris: Time Minimizing, Energy Maximizing and the Annual Cycle Organization. Oecologia 67: 331 - 337.

Maia CT, Dorigo TA, Rocha CFD. 2012. Influences of seasonality, thermal environment and wind intensity on the thermal ecology of Brazilian sand lizards in a restinga remnant. South American Journal of Herpetology 7: $241-\quad 251$. https://doi.org/10.2994/057.007.0306.

Melville J, Swain R. 1997. Daily and seasonal activity patterns in two species of high altitude skink, Niveoscincus microlepidotus and Niveoscincus metallicus, from Tasmania. Journal of Herpetology 31(1): 29.

Phung THT. 2013. Research on biological and ecological characteristics of the Long-tailed Sun Skink Eutropis longicaudata (Hallowell, 1856) in artificial feeding conditions from Quang Tri Province. M.Sc. Thesis, Hue University, Hue, Vietnam. 68.

Reilly SM, Mc Brayer LD, Miles DB. (Eds.). 2007. Lizard Ecology: The Evolutionary Consequences of Foraging Mode. Cambridge University Press: Cambridge.

Shea G, Allison A, Tallowin O, McGuire J, Iskandar D, Cai B, Wang Y, Yang J, and Shang G. 2018. Eutropis multifasciata. The IUCN Red List of Threatened Species 2018: e.T195295A2376842.

Spellerberg F. 1972. Thermal ecology of allopatric lizards (Sphenomorphus) in southeast Australia. III. Behavioural aspects of thermoregulation. Oecologia 11: 1-16.

Truong TM. 2005. Species composition and biological and ecological characteristics of the genus Eutropis (Fitzinger, 1843) in Khanh Hoa Province. M.Sc. Thesis, Hue University, Hue, Vietnam. 58 p.

Truong PB. 2013. Species composition and biological characteristics of some skinks of the genus Eutropis (Fitzinger, 1843) in Buon
Don District, Dak Lak Province. M.Sc. Thesis, Hue University, Hue, Vietnam. 63 p.

Vitt LJ, Caldwell JP. 2009. Herpetology. Burlington (MA): Academic Press.

Wapstra E, Swain R, O’Reilly JM. 2001. Geographic variation in age and size at maturity in a small Australian viviparous skink. Copeia 2001: 646-655. DOI: 10.1643/0045-8511.

Wapstra E, Uller T, Sinn DL, Olsson M, Mazurek K, Joss J, and Shine R. 2008. Climate effects on offspring sex ratio in a viviparous lizard. Journal of Animal Ecology 78: 84-90. DOI: 10.1111/j.1365-2656.2008.01470.x.

Yuni LPEK. 2002. Time Energy Budget of the New Holland honeyeater Phylidonyris novaehollandiae (Aves: Meliphagidae) near Hobart, Tasmania. MSc. Thesis. University of Tasmania, Australia. 132 pp.

Yuni LPEK, Jones SM, Wapstra E. 2015. Energy expenditure of the spotted snow skink, Niveoscincus ocellatus, at two climatic extremes of its distribution ranges. Journal of Thermal Biology 52: 208-216. doi: 10.1016/j.therbio.2015.07.003

Yuni LPEK, Jones SM, and Wapstra E. 2018. Thermal biology of the spotted snow skink, Niveoscincus ocellatus, along an altitudinal gradient. Australia Journal of Zoology 66: 235-246. https://doi.org/10.1071/ZO18014. 